\title{
SURFACE MOUNTING OF LEADLESS CHIP CARRIERS ON VARIOUS PRINTED CIRCUIT BOARD TYPE SUBSTRATES*
}

\author{
I.G. LANG \\ Exacta Circuits Limited, Selkirk, Scotland \\ (Received November 12, 1981; in final form March 5, 1982)
}

The effect of extended thermal cycling on the reliability of joints between ceramic leadless chip carriers and various printed circuit board type substrates is examined. Test results indicate success in using ceramic leadless chip carriers on some styles of PCB.

\section{INTRODUCTION}

It is increasingly well accepted that the chip packaging revolution from dual in line to chip carrier (CC), tape automated bonding (TAB) and bare chip (BC) is under way, brought about by integration at chip level.

This change prompts the need for change, in turn, on the next level of interconnection.

Broadly a need is seen for:-

- increased packing density of components.

- more control of electrical and other performance requirements.

Some previous work has indicated that PCB technology is capable of meeting the challenge of the new interconnection requirement at typically printed wiring board type costs.

\section{PCB TECHNOLOGY}

Conventional high volume technology will produce the following:-

$\begin{array}{ll}\text { Smallest Hole (min) } & 0.013 " \\ \text { Ratio - Board Thickness to } & \\ \text { Hole size (max) } & 5.4: 1 \\ \text { Number of layers } & 14 \\ \text { Size (max) } & \text { Ca 24" } \times 24 " \\ \text { Dielectric Separation } & 0.0025 " \text { to } 0.004 \text { " } \\ \text { Conductor Width (min) } & 0.006 " \\ \text { Gap width (min) } & 0.006 " \\ \text { Conductor Thickness (min) } & 0.0005 " \\ \text { Thermal resistance } & \text { Fair } \\ \text { Dielectric properties } & 2 \text { to } 5\end{array}$

Slight modification to manufacturing methods are required to better these figures - See Figure 1, but it is not the intention of this paper to elaborate further on these products rather just to draw attention to the dimensions and properties available which match the changing needs of interconnection.

*Paper originally given at the Technical Sessions Programme at Productronica, Munich, November, 1981. 
Developing technology for PCBs

\begin{tabular}{lr}
\hline Smallest Hole (min) & $0.004 "$ \\
Ratio-Board Thickness to & $3: 1$ \\
Hole Size (max) & 6 \\
Number of layers & " 8 8" \\
Size (min) & $.002 "$ \\
Dielectric Separation & $.004 "$ \\
Conductor Width (min) & $.004 "$ \\
Gap Width (min) & $.0002 "$ \\
Conductor Thickness (min) & Good \\
Thermal Resistance & 2 to 5 \\
Dielectric Properties & \\
\hline
\end{tabular}

FIGURE 1 (Table) Developing Technology for PCBs.

\section{DISCUSSION OF COEFFICIENT OF EXPANSION MISMATCH}

One area however where there has been debate is the use of components with a particular coefficient of expansion on a substrate which has a different value for the coefficient. It is expected that you can accept the long term proven reliability of the PCB when dealing with leaded or socketed components and a great deal of activity is current in producing leaded or leadless plastic chip carriers which will similarly match the PCB. If however, continuing greater use of ceramic leadless chip carriers is made then it needs to be demonstrated that high joint reliability can be achieved.

The published work of Fennimore ${ }^{1,2}$ Settle $^{3}$ Minnetti $^{4}$ and Lassen ${ }^{5}$ are all reports of varying success on this subject. No one has attempted to explain why these empirical experiments should have been successful.

In practice the joint area is complex and multiple. The stress relieving properties of metallic leads or of solder pillars are well understood. Ductility. hardness, toughness and creep effects also play a part - See Figure 2.

The joint may however be looked at in a more simplistic model; and the expected stress resulting from the thermally introduced strain may be considered as being proportional to the area of the joint, the difference in the coefficients of expansion, the temperature difference from the stable, no stress state, and an elasticity factor.

One ready way to ensure minimum stress is therefore to match the coefficients of expansion. Another is to limit the thermal excursions.

M. El Refaie ${ }^{6}$ has demonstrated that the stress relieving effect of having an elastomer as part of the system will reduce the effective modules of elasticity for the combined system to a very low figure.

Additionally modern PCB substrates are not necessarily totally homogenous and many properties, including the linear coefficient of expansion (C.O.E.) can vary in the $\mathrm{X}, \mathrm{Y}$ or $\mathrm{Z}$ directions in any plane.

If one considers the common woven glass reinforced epoxy resin substrate, (See Figure 3 ), then the glass reinforcement normally controls the bulk coefficient of expansion in the $\mathrm{X}$ and $\mathrm{Y}$ axes, being different in $\mathrm{X}$ and $\mathrm{Y}$ unless there is a perfectly balanced weave. However in the $\mathrm{Z}$ axis the C.O.E. tends to be nearer to that of the epoxy resin part of the substrate. If then one were to consider a resin free surface to such a substrate then the C.O.E. at the surface in the $\mathrm{X}$ and $\mathrm{Y}$ plane would relate more to the glass properties. If however there was to be a resin rich layer on the surface of the substrate then the C.O.E. of the surface would be nearer that of the resin. 

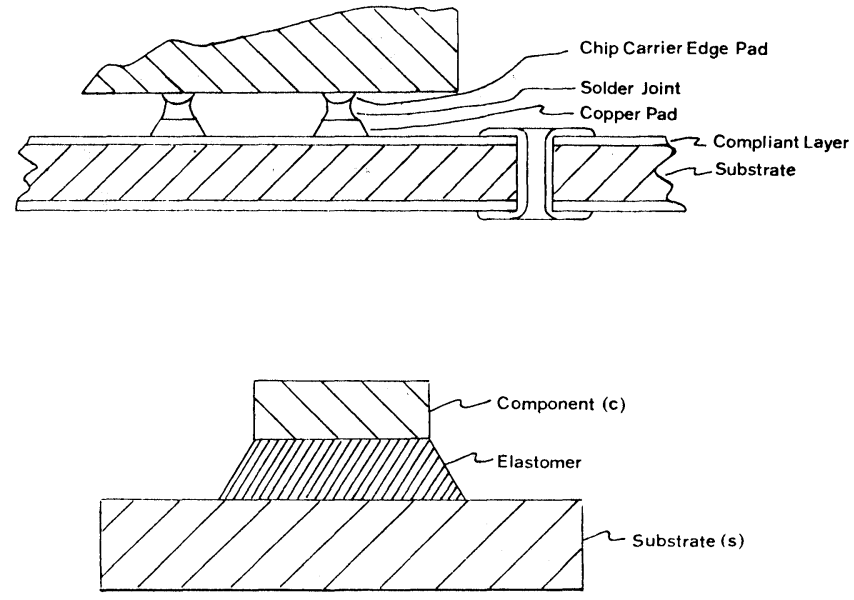

Force $\propto$ Area $\times($ Coeff of Exp Diff $) \times \Delta T \times \frac{\varepsilon_{s}}{\frac{\varepsilon_{s}}{\varepsilon_{c}}+1}$

TYPICAL Coeff of Exp 10 to $20 \times 10^{-6}$

5 to $7 \times 10^{-6}$

$\mathcal{E}_{\mathrm{s}} \bumpeq 0.02100 .2 \times 10^{6}$

$\mathcal{E}_{\mathrm{c}} \Omega 10 \times 10^{6}$

FIGURE 2 Attachment Systems and Stress Module for Joining Components to PCBs.

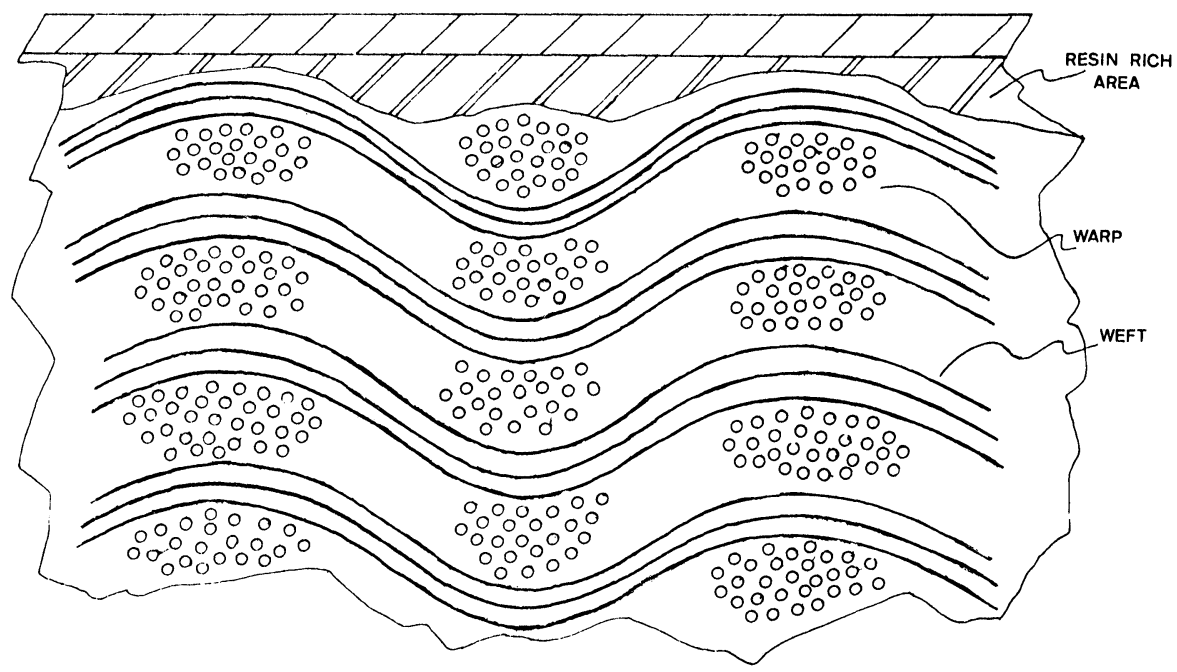

FIGURE 3 Typical Substrate Construction. 
TABLE II

\begin{tabular}{|c|c|c|c|c|c|c|}
\hline \multicolumn{5}{|c|}{ Chip Carrier Type } & \multirow[t]{2}{*}{ Cup Lid } & \multirow{2}{*}{$\begin{array}{c}\text { Total } \\
\text { Weight } \\
\text { gms }\end{array}$} \\
\hline Pads & Layers & Supplier & Part No. & $\begin{array}{c}\text { Dimensions } \\
\text { mm } \\
\text { (excluding lid) }\end{array}$ & & \\
\hline 16 & 1 & $3 \mathrm{M}$ & ST $88-16 C N$ & $7.62 \mathrm{SQ} \times 0.51$ & Kyocera KKC-10180 & 0.26 \\
\hline 28 & 1 & Kyocera & CS52811 & $11.43 \mathrm{SQ} \times 0.56$ & Kyocera KKC-10188 & 0.65 \\
\hline 44 & 1 & Kyocera & CS54402 & $16.51 \mathrm{SQ} \times 0.81$ & Kyocera KKC-10183 & 1.36 \\
\hline 52 & 5 & $3 \mathrm{M}$ & SR88-52BA & $19.05 \mathrm{SQ} \times 1.91$ & STL flat lid & 2.60 \\
\hline
\end{tabular}

Lids sealed with Kyocera LTS (Low Temperature Sealant) Epoxy

FIGURE 4 Chip Carrier Details (Table).

Similarly however the modulus of elasticity of the combined system in bulk will not be the same as that obtained at the surface given either a resin free or resin rich zone.

Do such considerations work out in practice? Will a leadless ceramic chip carrier effectively float on the shock absorbing elastomeric layer? Does this concept help to explain some of the previously published results?

TABLE III

\begin{tabular}{|c|c|c|c|c|}
\hline Type No. & Type & Suppliers Designation & Build Up & TEC PPM ${ }^{\circ} \mathrm{C}$ \\
\hline 1 & $\begin{array}{l}\text { FR2 } \\
\text { Phenol/Paper }\end{array}$ & $\begin{array}{l}\text { Isola } \\
\text { Supra-Carta } 96 \\
\text { VO-350 }\end{array}$ & \multirow{4}{*}{$\begin{array}{l}1.6 \mathrm{~mm} \\
\text { Double Clad } \\
1 \mathrm{oz} \text { copper }\end{array}$} & $\begin{array}{l}20\left(80^{\circ} \mathrm{C}\right) \\
(50 / 100 \\
\text { shrinkage at } \\
\left.120^{\circ} \mathrm{C}\right)\end{array}$ \\
\hline 2 & $\begin{array}{l}\text { FR4 } \\
\text { Epoxy/Glass }\end{array}$ & $\begin{array}{l}\text { Double Clad } \\
\text { Micaply } \\
\text { EC818T/FR-4/GFN }\end{array}$ & & $\begin{array}{l}10 \text { warp } \\
15 \text { weft }\end{array}$ \\
\hline 3 & $\begin{array}{l}\text { Polyimide/ } \\
\text { Glass }\end{array}$ & $\begin{array}{l}\text { Double-Clad Micaply } \\
\text { PG-418-T }\end{array}$ & & $\begin{array}{l}9 \text { (warp and } \\
\text { weft close) }\end{array}$ \\
\hline 4 & $\begin{array}{l}\text { Modified } \\
\text { Polyimide } \\
\text { Kevlar }\end{array}$ & $\begin{array}{l}\text { Howe HI-6938/120 } \\
\text { Kevlar }\end{array}$ & & 5 to 5.5 \\
\hline 5 & $\begin{array}{l}\text { Polyimide } \\
\text { coated } \\
\text { epoxy/ } \\
\text { glass }\end{array}$ & $\begin{array}{l}\text { Exacta } \\
\text { Elastomer coated } \\
\text { substrate-1 } \\
(\text { ECS-1) }\end{array}$ & $\begin{array}{l}1.6 \mathrm{~mm} \text { epoxy } / \text { glass } \\
\text { clad one side } 1 \mathrm{oz} \\
\text { copper. Polyimide } \\
\text { flexible coated other } \\
\text { side and clad } 2 \mathrm{oz} \\
\text { copper }\end{array}$ & \\
\hline 6 & $\begin{array}{l}\text { Adhesive } \\
\text { coated } \\
\text { epoxy/ } \\
\text { glass }\end{array}$ & $\begin{array}{l}\text { Exacta Elastomer } \\
\text { coated substrate-2 } \\
(\mathrm{ECS}-2)\end{array}$ & $\begin{array}{l}1.6 \mathrm{~mm} \text { epoxy/glass } \\
\text { adhesive coated } \\
\text { both sides. } \\
\text { Double clad } 1 \mathrm{oz} \\
\text { copper }\end{array}$ & \\
\hline 7 & $\begin{array}{l}96 \% \\
\text { alumina } \\
\text { ceramic }\end{array}$ & $\begin{array}{l}\text { Coors } \\
\text { ADS-95F }\end{array}$ & $0.62 \mathrm{~mm}$ & $\begin{array}{l}6.0 \\
\left(25-200^{\circ} \mathrm{C}\right)\end{array}$ \\
\hline
\end{tabular}

FIGURE 5 Substrate Construction Details (Table). 


\section{MATERIALS ON TEST}

\section{Chip Carriers}

Single layer construction ceramic leadless chip carriers were used. Four sizes, 16, 28, 44 and $52 \mathrm{pad}$ varieties were obtained from $3 \mathrm{M}$ Co. and Kyocera, complying generally to JEDEC standard type MS004 0.050" centre leadless type C (See Figure 4).

\section{Printed Circuits}

Six different card materials were used together with an alumina ceramic control with matched expansion (See Figure 5).

\section{TEST METHODS}

\section{Test Coupon Design}

This was based upon the minimum size on which at least one of each size of carrier could be mounted. This also provided for ease of microscopic inspection of the solder joints from all angles. Carrier failure was defined as failure of a single joint. The coupon size was $95 \times 50 \mathrm{~mm}$ and on the basis of equalising the total number of joints on test per carrier size, $3 \times 16$ pads, $2 \times 28$ pads, $1 \times 44$ pad and $1 \times 52$ pad carriers were used per coupon (pad sizes). (See Figure 6).

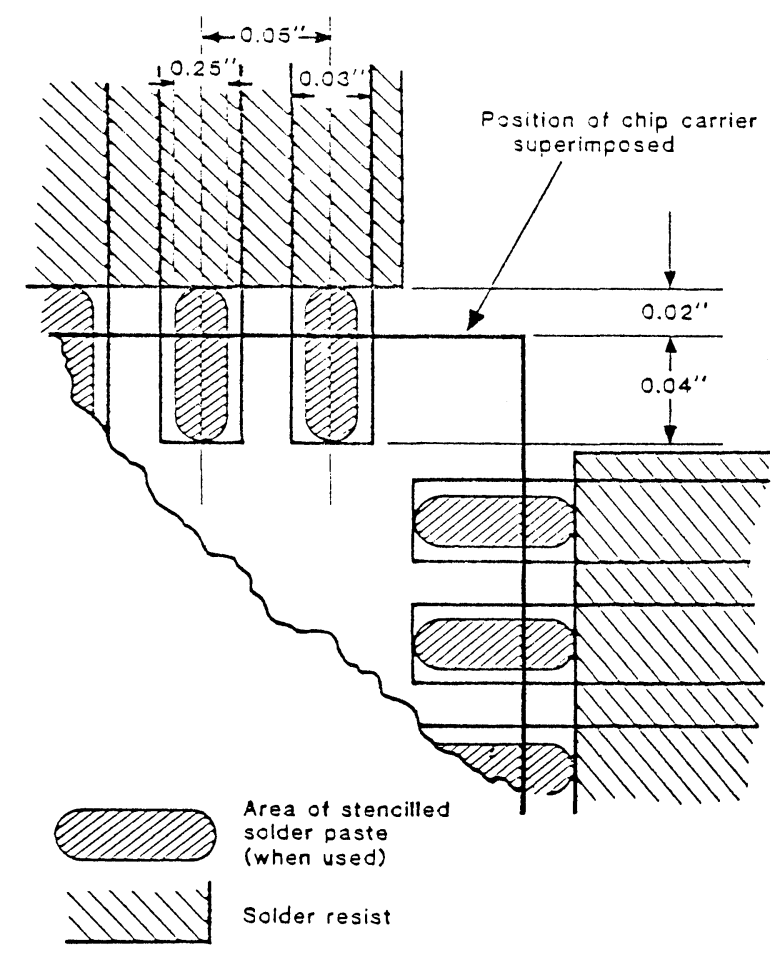

FIGURE 6 Solder Pad and Solder Resistor Dimensions showing one corner of foot print. 


\section{Thermal Cycling}

There is much discussion as to the relevance of thermal cycling to real life conditions. The tests were conducted in a Montfort oven equipped with circulating fan and boost heater, the cooling being effected by liquid carbon dioxide. To ensure adequate temperature uniformity the area used within the chamber was restricted to one third of a square metre. The tests were conducted in accordance with MIL STD 833B method 1010.2 Condition B

$$
\text { i.e. } \quad-55^{\circ} \mathrm{C} \quad 10 \text { minutes min }
$$

Time between extremes 5 minutes max.

In practice 2 cycles per hour were used.

\section{Inspection}

80 test coupons were mounted in $20 \times 75$ pin edge connectors in a frame. In operation a voltage was applied to each coupon in turn. Individual carrier selection was possible by a rotary switch leading to a LED display monitor. Joints were monitored and recorded at intervals, both electrically and by visual microscopic examination. Visual cracks in the solder were always preceded by surface crazing and no visually good joints were found be electrical failures.

\section{SOLDERING}

\section{Soldering Equipment}

Two varieties of soldering techniques were used, wave and reflow. A Schleuniger 'Jet' soldering machine - Type 6TF160 was used for the wave samples. The reflow soldering was performed in a Hedinaire VPD1 tank using a 3M Fluorinert 70 vapour.

\section{Soldering Conditions}

The finish on all the PCB style substrates was a fused layer of 63/37 tin/lead alloy which had previously been electroplated to 8 to 12 microns thick.

The ceramic control coupons were printed with $\mathrm{Pd} / \mathrm{Ag}$ conductors and pads.

Reflow soldering After lid sealing the carriers were dipped in molten 60/40 tin/lead solder at $230^{\circ} \mathrm{C}$ for 1 second using an organic water soluble flux (Superior 30) and were subsequently washed, checked for leakage and for continuity of internal wire bonds.

Solder paste was added to half the coupons for reflow soldering stenciling and drying at $85^{\circ}$ to $100^{\circ} \mathrm{C}$. The carriers were brushed with Frys FR8/500B MA flux and dried.

Solder resist was applied to all coupons with the extra solder paste and half the coupons without the extra solder paste.

Wave soldering Fry's GR8/500B MA flux was brushed on the coupons with a soldering time of about 3 seconds and belt speed of 0.25 metres/second. The coupons were cleaned to remove flux residues.

Component attachment Before soldering all carriers were held in place by Eccobond 285 adhesive which had been applied using a DEK printing screen. 
Solder thickness In practice the spacing between the carrier and the coupon was unaffected by the quantity of solder used or by the use of the solder resist pattern, being $0.125 \mathrm{~mm}$ of which $0.035 \mathrm{~mm}$ was due to copper tracking. Any extra solder at the joint formed a build up at the side channels of the carrier.

\section{RESULTS}

\section{Visual}

The results of the testing are summarized in Figures 7 and 8 . Figure 7 gives the data obtained for different substrate materials and soldering method, using different pad sizes. Fig. 8 simplifies the data for one pad size.

The common sequence of failure was along one side of a carrier followed by the joints on adjacent sides beginning with those nearest the failed row. Individual joint failure was unusual. The coupons were inspected after 99, 135, 224, 270 and 432 cycles are displayed in Figure 6.

\section{Discussion}

(i) Of the conventional materials FR2 is relatively bad, whereas FR4 provides poor yet not exactly unuseable performance results particularly if more work were to be performed on soldering techniques etc. Polyimide/glass is marginally better than FR4.

(ii) There were no failures of connection for the matched expansion materials, i.e. the ceramic control batch or the Kevlar reinforced polyimide.

(iii) The two elastomer coated substrates demonstrates good results with no failures for the wave soldered samples.

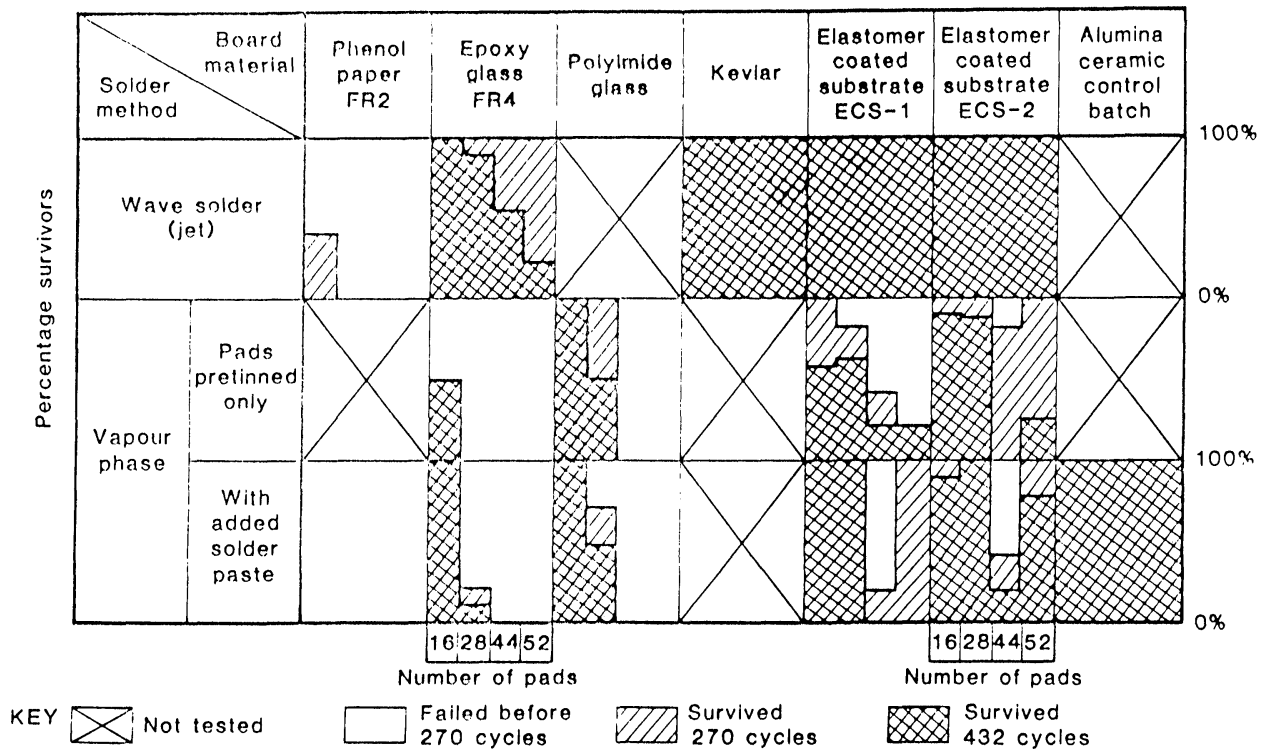

FIGURE 7 Thermal Cycling Performance - Variation with Substrate Material and carrier size (Temperature cycles $-55^{\circ} \mathrm{C}$ to $+125^{\circ} \mathrm{C}$ ). 


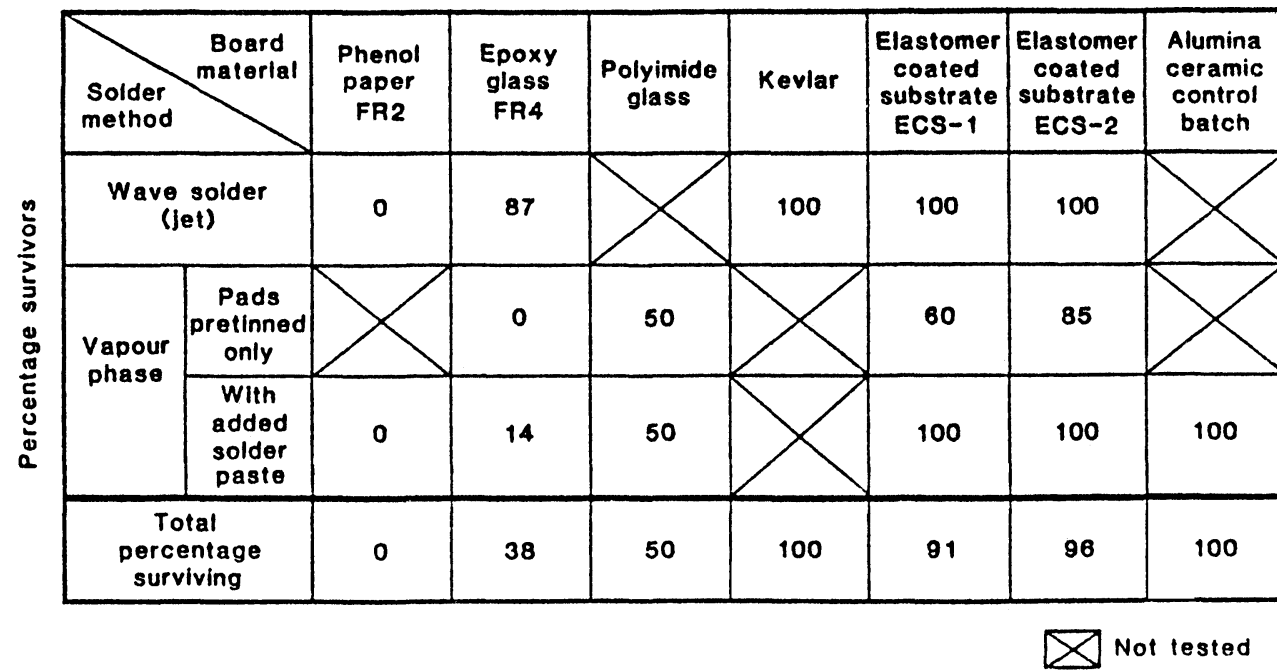

FIGURE 8 Thermal Cycling Performance of 28 Pad Carriers $\left(432\right.$ cycles $-55^{\circ} \mathrm{C}$ to $+125^{\circ} \mathrm{C}$ ).

(iv) Earlier failure of the larger carrier sizes confirms publishing work on fatigue and was noticeable particularly on the soldering techniques/materials which general gave the poorer results.

(v) The 28 pad size was less critically effected by process variations.

(vi) The 55 pad carrier fared relatively badly compared to other carrier sizes. It was noted that these particular carriers had a smaller metallised edge radius which effectively reduced the volume of solder related to each individual pad.

(vii) Wave soldering gave better and more consistent results.

(viii) Reflow soldering gave relatively poorer results particularly when there was no added solder paste.

\section{CONCLUSION}

Leadless chip carrier mounting on to various substrates was performed and thermally stressed to simulate life conditions.

The following conclusions were reached.

(i) Limited life is possible on conventional printed circuit board materials and this solution will be within normal price and availability.

(ii) Excellent life is possible on certain expansion matched substrates but these may be expensive solutions.

(iii) Excellent life is also possible using certain elastomer coated substrates manufactured using relatively conventional methods and materials and within the normal price range and availability. 


\section{ACKNOWLEDGEMENTS}

The Author is grateful to the following for experimental results:-

Dr. M. El Refaie (Exacta Circuits Limited) and to the Research and Development

Engineers of Exacta. Also D. Fishman, (Standard Telecommunication Laboratories Limited, Harlow).

\section{REFERENCES}

1. J.E. Fennimore "Using Leadless Components Technology on Printed Wiring Boards" Electronic Packaging and Production, pp 128-132, December 1979.

2. J.E. Fennimore "Hermetic Ceramic Chip Carrier Implementation" Electronic Packaging and Production, pp 127-181, May 1981.

3. R.E. Settle, "A New Family of Microelectronic Packages for Avionics", Solid State Technology, pp 54-58, June 1978.

4. R.H. Minetti, "Solid Phase Solder Bonding for Use in The Assembly of Micro Electronic Circuits", Proc. of 1980 International Microelectronics Symposium (ISHM), pp 126-129, 1980.

5. C.L. Lassen, "Use of Metal Cor Substrates for Leadless Chip Carrier Interconnection" Electronic Packaging and Production, pp 98-104, March 1981.

6. M. E1 Refaie, Private Communication, Patent Application No. 8113873, 1980. 

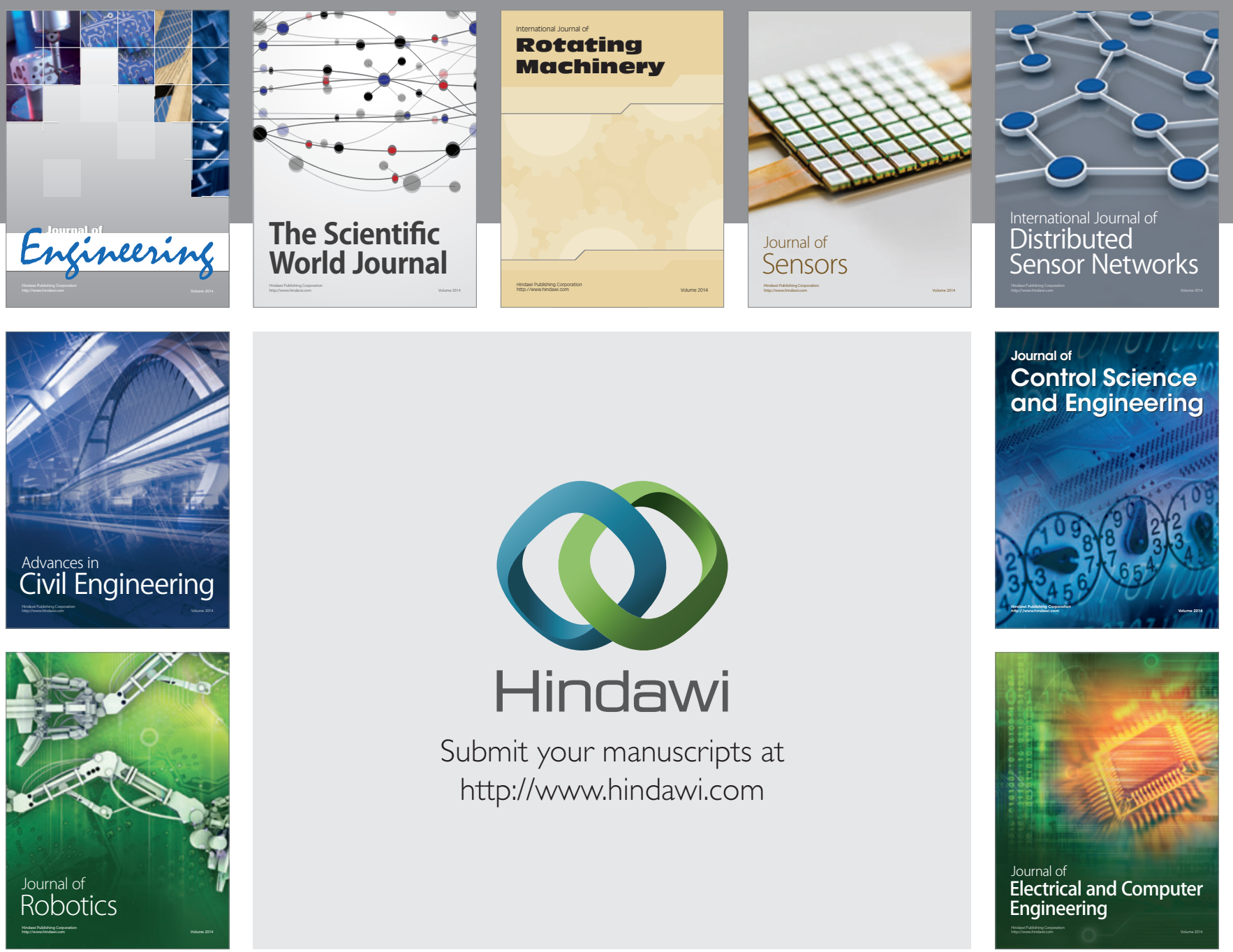

Submit your manuscripts at

http://www.hindawi.com
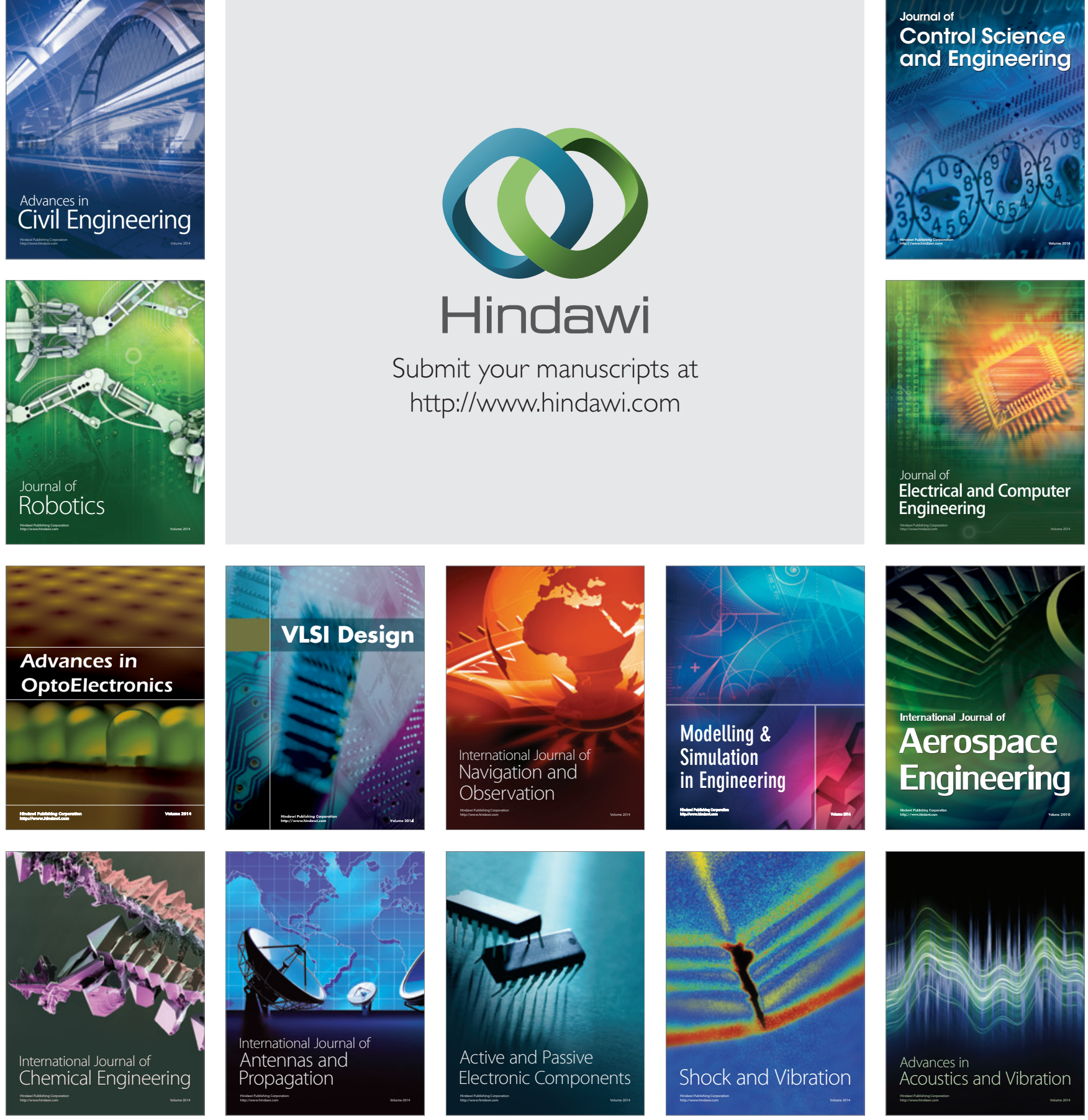